\title{
Mental disorders predicted all cause and cause specific deaths in Finnish adults
}

Joukamaa M, Heliövaara M, Knekt P, et al.Mental disorders and cause-specific mortality. Br J Psychiatry 2001

Dec;179;498-502.

QUESTION: In adults $\geqslant 30$ years of age, do mental disorders predict all cause and disease specific mortality?

Design

Cohort study with 15 to 17 years of follow up (part of the Mini-Finland Health Survey)

\section{Setting}

69 municipalities in Finland.

\section{Participants}

Participants were recruited from a nationally representative sample of 8000 Finnish adults $\geqslant 30$ years of age (54.5\% women).

\section{Assessment of risk factors}

Participants were screened between 1977 and 1980 using the 36 item version of the General Health Questionnaire and the Present State Examination for any mental disorder, functional psychoses, mood disorders, and all neuroses.

\section{Main outcome measures}

All deaths and cause specific deaths.

\section{Main results}

After 15-17 years (80 089 person y) of follow up, 1597 deaths occurred; 876 deaths were caused by cardiovascular disease ( 537 by coronary disease, 192 by cerebrovascular disease), 130 by respiratory disease, 341 by cancer, 72 by non-suicidal injuries, and 20 by suicide. The presence of any mental disorder or schizophrenia at baseline was associated with an increased risk of all cause deaths and most cause specific deaths (table). All cause deaths were predicted by functional psychosis in both men and women, and by mood disorders or neurotic depression in men but not in women.

\section{Conclusion}

In Finnish adults, the presence of any mental disorder or schizophrenia predicted the risk of all cause deaths and most cause specific deaths.

\section{website $e x t r a$ \\ Additional information appears on the Evidence-Based Mental Health \\ website \\ www.ebmentalhealth.} com

Source of funding:

Social Insurance

Institution of Finland.

For correspondence: Dr M Joukamaa, Oulu University Hospital, Oulu, Finland. matti.joukamaa@oulu.fi

\section{COMMENTARY}

The study by Joukamaa et al investigated the mortality risks associated with mental disorders using data from a long term follow up cohort. It is already well known that psychiatric patients are at risk of premature death, but most previous studies were based on clinical populations. ${ }^{1}$ The present study is important and has a number of strengths: it is representative of the Finnish population, had a long follow up, used good methodology, and estimated the risk of death. Limitations of the study included relying on official statistics for outcomes, limited power for rare events, and lack of control for important confounders such as lifestyle factors.

Not surprisingly, it has confirmed many previous findings, such as the elevated risk of suicide in mental disorders. New findings include a markedly elevated risk of respiratory deaths in those with mental disorder and sex differences in mortality. More men with schizophrenia died of common respiratory conditions than of suicide. These findings may be due to factors such as smoking and substance abuse. ${ }^{1}$ Psychotropic medications may also have an impact on mortality. Previous work has shown that poor access to and quality of healthcare interventions contribute to excess mortality in those with mental disorders. ${ }^{2}$ This has important implications. Mental health workers should not only focus on the psychological aspects of care, but also provide health education and enable access to good health care. Primary care providers may be encouraged that the effort and expense to engage those with mental disorders could have a substantial effect on their health. Policy makers should also take note: recent efforts to reduce the suicide risk is commendable, but common and achievable targets such as cardiovascular and respiratory disease may also have a large effect on mortality. Finally, future research should address issues such as the causes for the elevated risk, health attitudes and behaviours of those with mental disorders, and interventions to improve health care in this group. Andre Strydom, MBChB , MRCPsych University College London London, $U K$

1 Harris EC, Barraclough B. Excess mortality of mental disorder. $\mathrm{Br} J$ Psychiatry 1998; 173:11-53.

2 Druss BG, Bradford WD, Rosenheck RA, et al. Quality of medical care and excess mortality in older patients with mental disorders. Arch Gen Psychiatry 2001;58:565-72.

Relative risks (RRs) of death in men and women with mental disorders at baseline

\begin{tabular}{llll} 
Disorder at baseline & Cause of death & RR (95\% Cl) in men & RR (Cl) in women \\
\hline \multirow{2}{*}{ Any mental disorder } & All deaths & $1.6(1.3$ to 1.8$)$ & $1.4(1.2$ to 1.6$)$ \\
\hline & Cardiovascular deaths & $1.3(1.1$ to 1.7$)$ & $1.4(1.1$ to 1.7$)$ \\
\hline & Non-suicidal injuries & $2.9(1.5$ to 5.5$)$ & $1.9(0.9 \text { to } 4.0)^{\star}$ \\
\hline & Suicides & $5.1(1.9$ to 13.6$)$ & $12.0(1.2$ to 115.8$)$ \\
\hline & Coronary deaths & $1.4(1.1$ to 1.8$)$ & $1.4(1.1$ to 1.9$)$ \\
\hline Schizophrenia & Respiratory deaths & $2.1(1.2$ to 3.5$)$ & $1.8(1.0$ to 3.2$)$ \\
\hline & All deaths & $3.3(2.2$ to 4.9$)$ & $2.3(1.3$ to 3.8$)$ \\
\hline & Respiratory deaths & $9.5(3.8$ to 23.8$)$ & $8.3(2.6$ to 26.8$)$ \\
\hline & Cardiovascular deaths & $2.9(1.7$ to 5.2$)$ & $1.6(0.7 \text { to } 4.0)^{*}$ \\
\hline & Suicides & $12.4(2.8$ to 54.7$)$ & data not provided \\
\hline & Coronary deaths & $2.4(1.1$ to 5.1$)$ & $1.2(0.3 \text { to } 4.9)^{\star}$ \\
\hline & Cerebrovascular deaths & $3.7(1.2$ to 11.8$)$ \\
\hline
\end{tabular}

${ }^{*}$ Not significant. 